\title{
Discriminación racial y el principio de igualdad
}

\author{
Rodrigo Lillo $V^{*}$
}

\begin{abstract}
For the first time in Chile, a Court of law sanctioned against discriminatory behavior based on race. In this text it is intented to describe the reasoning of the judicial veredict, wich assumes the liberal principles and the human rights doctrine. Besides it is explained the inadequateness of the equality principle from Kant's moral philosophy, facing the interethnic antagonism, although nowadays, the question of the indigenous rights, it is not consider on the no individual discrimination, but in the recognition of the political rights of the indigenous peoples.
\end{abstract}

\section{Resumen}

Por primera vez en nuestro país, un Tribunal sanciona una conducta discriminatoria basada en criterios raciales. En el texto que sigue, se intenta describir el razonamiento que, siguiendo los principios liberales y de la Doctrina de los Derechos Humanos, fundamentan el fallo judicial. Además se plantea el desafio y posibilidad que constituye el principio de la igualdad pensado desde la filosofia moral de Kant- como aporte a la resolución del conflicto interétnico.

\section{Introducción}

$\mathrm{E}$ 1 pasado 8 de septiembre de 1999 , por primera vez un Tribunal chileno, en aplicación de diversas normas juridicas, sanciona una conducta que consideró como una discriminación manifiesta e intencionada en contra de los indigenas (véase Anexo). ${ }^{2}$ En su sentencia, la Corte de Apelaciones de Temuco, ha castigado el comportamiento de una funcionaria municipal, por considerar que se enmarca dentro de la conducta que la Ley Indigena define como ilícita y antijurídica, en su artículo $8^{\circ}$. Como quedará explicado, nuestro orden juri- dico excluye todo tipo de discriminación racial, y la Corte ha establecido que una acción como la realizada por la funcionaria sancionada, constituye una discriminación "manifiesta e intencionada". Se establece, asi, un precedente en esta materia.

De esta forma, el fallo del Tribunal de alzada, no sólo puede constituirse en hecho relevante en el marco de las reivindicaciones del pueblo mapuche, sino que confirma los valores de la diversidad y la igualdad, como aspectos fundamentales de nuestra democracia.

En efecto, el reconocimiento de este principio juridico fundamental - el de la no discriminación racial -, y la exclusión de toda acción que tienda a quebrantaria, debe entenderse como un avance positivo en las relaciones interétnicas, que se han desarrollado hasta ahora de manera conflictiva. La adecuada interpretación del principio de igualdad, expresado en el reconocimiento judicial del derecho a ser tratado como igual, ${ }^{2}$ podría constituir una herramienta eficaz en el intento por promover unas relaciones interculturales más simétricas entre el pueblo mapuche y el Estado chileno.

\section{¿Qué sanciona la Corte de Apelaciones?}

La Asistente social mapuche, Bernardita Calfuqueo Llancapán, se desempeñó como tal en el consultorio de salud municipal de Lumaco, durante el año 1998. Alli recibió un tratamiento diferente en materia profesional, durante gran parte de su estadia, manifestado en una serie de actitudes y hechos, siendo jurídicamente el más relevante, el to pago de parte de sus remuneraciones (horas extraordinarias y viáticos). La persona encargada de hacer dichas cancelaciones, se funcó persistentemente en razones que no tienen asidero jurídico ni legal. Que, los argumentos utilizados, no aparecieron - desde el primer momento - como plausibles, por scr esgrimidos por quien debiera conocer dichas normas, dejando en evi-

\footnotetext{
- Abogado, Fundación Instituta Indigena, Obispado de Temuco.
}

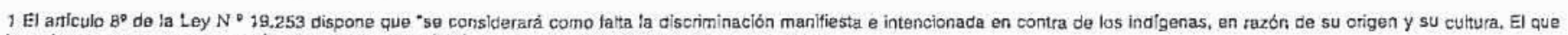
incurriere en esta conducta será sancionado con multa de uno a cinco ingresos mínimos mensuales".

2 Ver DWOAKIN, R. (1989), "Los Derechos en serio", Editonal Ariel derecho, Barcelona, Espana, (pág. 332). 
dencia que se ocultaba la verdadera razón de este incumplimiento. Los motivos reales quedaron al descubierto más tarde, cuando la funcionaria expresa ciertas apreciaciones raciales negativas respecto de los mapuche, etnia a la que pertenece la querellante.

Más allá del problema probatorio, que plantea todo juicio sobre discriminación -y que aquí se resolvió por la declaración de un testigo presencial y la aplicación de reglas menos rígidas que el sistema general de apreciación de la prueba establecida en nuestro ordenamiento procesal- ${ }^{3}$ lo fundamental de la tesis judicial sostenida en la sentencia de la Corte, es que una actitud como la ejercida por la infractora, es contraria a derecho y digna de sanción moral y jurídica.

Ahora bien, la contravención no está constituida aquí, por la consideración falsa y prejuiciosa que la transgresora tiene de Ios mapuche, y que le expresara directamente a su victima, Bernardita Calfuqueo. No se sanciona la actuación ofensiva de la funcionaria sancionada, ni los insultos propinados en cuanto tales. El ilícito (discriminación manifiesta e intencionada en contra de los indigenas) está constituido, $\mathrm{y}$ así ha quedado establecido por el inédito fallo, por dos elementos copulativos : i) un tratamiento distinto respecto del resto, y ii) un motivo prohibido por el derecho (discriminación directa). ${ }^{4}$ De tal manera que, en este caso, la discriminación ha consistido en el no pago de ciertas remuneraciones legalmente procedentes a una funcionaria mapuche, motivado por la opinión negativa que la autoridad administrativa encargada del pago, tiene de aquellas personas que pertenecen a este pueblo indígena. Señala el Tribunal sobre este punto: “...asi las cosas, ha quedado demostrado que la querellada, caprichosa e irracionalmente, se negó a conceder el beneficio de los viáticos a la ofendida, encontrándose tal negativa fundada en la calidad de indigena de ésta, lo cual constituye una discriminación manifiesta e indiscriminada $(\text { sic })^{5}$ en razón del origen y cultura de la querellante...".

De esta manera se ha entendido por los sentenciadores la infracción sancionada en el artículo $8^{\circ}$ de la Ley $\mathrm{N}^{\circ} 19.253$. No obstante, en su fallo, los jueces aluden igualmente a otras normas juridicas vulneradas. En efecto, éstas se refieren principalmente al principio de la igualdad y a la no discriminación (como uma derivación de aquel) -consagrado en diversas normas del ordenamiento juridico fundamental chileno-. Este principio se encuentra consagrado de manera genérica en La Convención Americana de Derechos Humanos, "Pacto de San José de Costa Rica", que en el artículo 24 consagra la igualdad ante la ley, excluyendo la discriminación. Asimismo, el fallo hace referencia a la "Convención Internacional sobre eliminación de todas las Formas de Discriminación Racial" que, complementando la norma del artículo $8^{\circ}$ de la Ley $\mathrm{N}^{\circ} 19.253$, define la discriminación como "toda distinción, exclusión, restricción o preferencia basada en motivos de raza, color, linaje u origen nacional o étnico que tenga por objeto o por resultado anular o menoscabar el reconocimiento, goce o ejercicio, en condiciones de igualdad, de los derechos humanos y libertades fundamentales en las esferas politica, económica, social, cultural o en cualquier otra esfera de la vida pública". 6

\section{Igualdad y no discriminación}

La sentencia del Tribunal de alzada ha considerado reprochable la conducta de una funcionaria municipal, a la luz de los hechos de que da cuenta la causa y de las normas y principios jurídicos aplicables.

La disposición básica en este caso, está contenida en el artículo $8^{\circ}$ de la Ley Indígena, que excluye toda discriminación manifiesta e intencionada en contra de los indígenas. Se encuentra contenida aqui una aplicación práctica del principio de igualdad consagrado en las bases institucionales del ordenamiento jurídico chileno. El principio que se describe alli, y que ha sido profusamente desarrollado por los autores, tanto en el ámbito de la filosofia como de la politica, ha de ser interpretado correctamente a fin de no infringir en definitiva- el valor que se intenta proteger.

En efecto, y no obstante la unánime adscripción de todas las corrientes políticas a este principio, la aplicación del mismo ha generado consecuencias muy diversas según el modo de entender este concepto. En materia de los derechos de los indígenas (o de los pueblos indigenas), esto es un punto mury discutido desde la dictación de la actual legislación al respecto, y existen quienes, fundados en el mismo principio, reclaman su valor o su ilegitimidad.

De cara al razonamiento sobre el sentido de la igualdad, y siguiendo las tesis del filosófo anglosajón Ronald Dworkin, haremos una distinción previa, entre la igualdad como politica, y como derecho. La diferencia entre ambas la explica Dworkin al señalar que las políticas (o directrices políticas) corresponden al tipo de estándar que propone un objetivo que ha de ser alcanzado; generalmente, una mejora en aigủn rasgo económico, político o social de la comunidad...". ${ }^{7}$ Por otra parte, el autor define los principios - que son proposiciones que describen derechos- como un "estándar que ha de ser observado, no porque favorezca o asegure una situación económica, política o social que se considera de-

3 La sentencia definitiva, a diferencia de la de primera instancia, "estima que en el proceso se probó suficientemente la actitud da discriminación manifiesta e intercionada de la querellada..."

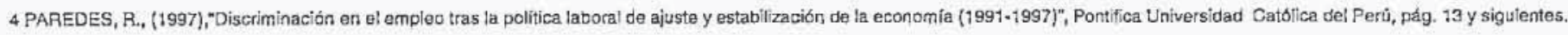

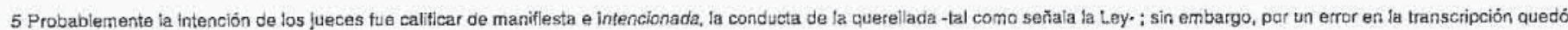
como aparece en el texto.

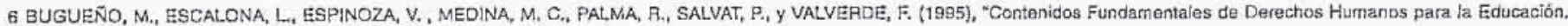
"Comiśón Nacional de Reparación y Reconcillación",

7 DWORKIN, F., op. cit., pảg. 72. 
seable, sino porque es una exigencia de la justicia, la equidad o alguna otra dimensión de la moralidad. De tal modo, la proposición de que es menester disminuir los accidentes de automóvil es una directriz, y la de que ningún hombre puede beneficiarse de su propia injusticia, un principio". ${ }^{8}$ Dworkin sostiene, además, que sólo los principios son vinculantes para los jueces en el ejercicio de la interpretación del derecho.

Ahora bien, respecto del tema que nos interesa, esto es, elucidar el sentido y alcance del derecho a la igualdad consagrado en la Carta Fundamental chilena, artículos $1^{\circ}$, inciso primero $19 \mathrm{~N}^{\circ} 2$ y 3 , debemos hacer una segunda distinción, a la que también recurre el profesor de Oxford, entre el derecho a igual tratamiento, que es el derecho a una distribución igual de oportunidad, recurso o cargas; y el derecho a ser tratado como igual, es decir, el derecho a ser tratado con la misma consideración y respeto. Sólo en algunas circunstancias, uno incluye al otro; sin embargo, sólo el segundo es fundamental, siendo el primero derivado. En efecto, aquel se encuentra consagrado en las bases de nuestro sistema jurídico social y dice relación con la concepción del hombre como un sujeto moral en sentido Kantiano. Es decir, como un individuo capaz de discernir su propio bien, de trazar un plan de vida a la luz de ese discernimiento, y de adecuar el conjunto de sus actos a ese plan. ${ }^{9}$ De esta forma se consagra la autonomía como un valor; y de otro modo, el más fundamental de los derechos, en tanto cuanto, por el sólo hecho de pertenecer a la clase de los humanos, tenemos acceso a los mismos derechos, y el hecho de ser privado de alguno de ellos (y por ende, del derecho a ser tratado como igual), significa considerar a alguien como menos que una persona.

En el caso que debió resolver la Corte, el derecho esgrimido incluía ambos tipos de derecho. El reclamo por un tratamiento sin distinción; el que a la luz de las normas aplicables era distinto del otorgado al resto de los funcionarios municipales. Que, a su vez, en el caso de Bernadita Calfuqueo, tiene el derecho a ser tratada como igual; esto es, al modo de un sujeto moral. Es decir, Bernardita Calfuqueo tenía derecho a ser tratada con respeto y seriedad, aún cuando pudiere existir la posibilidad jurídica de tener un tratamiento distinto; cuestión que, en este caso, tampoco es posible.

En efecto, el orden jurídico permite la instauración de diferencias, que no sean arbitrarias o irracionales tal como quedó establecido en la discusión de esta norma en la Comisión redactora de la Constitución. ${ }^{10}$ Que deben considerarse como tales, aquellas que poseen un carácter utilitarista. Es decir, aquellos justificarán la discriminación en tanto cuanto de ello se siga un beneficio o bienestar colectivo. Esto, por cuanto no resulta posible establecer una medición correcta de este beneficio y porque los parámetros de felicidad y del placer no son objetivables, sino que más bien son personalísimos. Que no es admisible señalar que esta se mide de acuerdo a las preferencias sociales, por cuanto estas corresponden predominantemente a una apreciación personal de cómo disfrutar ciertos bienes y oportunidades o a preferencias externas. Este argumento no otorga -en defintiva- una justificación compatible con el derecho a ser tratado como igual. Que, además, no es justo un criterio basado en esas preferencias en una sociedad como la nuestra, en que existe un prejuicio claro en contra de los mapuche. Sólo será admisible una discriminación tal, cuando respete un tal derecho.

De esta manera, el hecho de pertenecer a un grupo social y étnico distinto -pueblo mapuche-, no constituye un motivo que justifique un tratamiento distintivo en este caso, lo cual es explicitamente recogido por la legalidad chilena, $\mathrm{y}$ ahora, por nuestro sistema judicial.

Que este razonamiento será útil también para abordar el dilema planteado por la legislación indigenista actual, en cuanto al establecimiento de normas de discriminación positiva.

\section{El derecho de los mapuche a ser tratados como iguales y el conflicto interétnico}

Ahora bien, si bien entre nosotros el tema de la igualdad de las personas se encuentra resuelto como sociedad (lo que no excluye las contravenciones particulares como la que aqui se ha sancionado), el asunto parece complicarse cuando nos encontramos frente a personas que pertenecen a grupos culturales distintos, no constitutivos de minorías, sino de etnias.

En efecto, en este caso, el tema de la igualdad no significará solamente propender a ciertos grados de acceso a bienes o situaciones que para nosotros parecen valiosos, sino que se trata de cómo entablar un diálogo intercultural entre dos grupos culturales distintos.

El Estado chileno, circunscrito en una realidad global e histórica ha dado una respuesta errática e inocua a través del tiempo. En efecto, el discurso del Estado en relación a las etnias o pueblos indigenas ha consistido en el intento por absorverlas e incorporarlas a él, en el entendido que corresponden a formas primarias y menos perfeccionadas de civilización. Si bien esto puede entenderse en un contexto decimonónico, en el proceso de formación de los Estado- nación, en que se "requirió para su consolidación de procesos políticos y juridicos sobre la base de esta distinción entre lo público y lo privado. Su objetivo: centralizar, cohesionar y universalizar las pautas de conducta y la organización politica y social de los nacionales"; ${ }^{11}$ esta pers-

8 DWORKIN, R., ibid., pág. 72 y 73

9 Ver PENA, C., (1998), “¿Por quê necesitamos a Kant, en Pevista $\mathrm{N}^{2} 69$ del Centro de Estudios Públicos.

10 Ver EVANS, E, (1986),"Los Derechos Constitucionales", Ed. Juridica de Chile, Tomo II, palg 15

11 FAIES, L. y MATUS, V. (1999), "El derecho. Trama y conjura patriarcal", Lom edidones, pág. 30. 
pectiva aparece hoy a todas luces insostenible. Así, en un discurso oscilante del Estado, este siempre se ha caracterizado por un profundo desprecio por lo mapuche; y su legislación se ha referido a ella (con excepción de la actual legislación, y la Ley 17.729 del año 1972) con el sólo objeto de arrebatarle su territorio e incorporarlos a su sistema de desarrollo económico capitalista. Los mapuche "...fueron confinados a unas 3000 reducciones..."12 producto del proceso de radicación; en la década del ' 80 no pasaban de 600 , las que disponían de unas 350.000 hás.. ${ }^{13}$ Como sostiene Calbucura, "desde una perspectiva histórica, las premisas legales que el Estado ha impuesto han tenido como objetivo deslegitimar el fundamento jurídico del sistema de propiedad colectivo sobre la tierra. A su vez la transformación en propiedad individual de las Comuniđades Indígenas implica la abolición del status institucional de minoria étnica que los mapuche han ejercido". ${ }^{4}$ De esta forma, toda la legalidad y la acción del Estado durante el siglo pasado, y gran parte del presente, provocó el desposeimiento y desconocimiento de los mapuche; si bien la legislación vigente provoca un cambio profundo en el "sentir" del Estado, en relación con el pueblo mapuche, no logra -por sí sola- superar este signo de discriminación, al establecer una nomativa proteccionista o indigenista de Estado, etiquetando al mapuche como un sujeto incapaz frente a nuestro modelo de desarrollo y ante nuestro sistema cultural occidental,

El etnocentrismo parece ser inseparable del derecho. "La mirada binaria de las sociedades occidentales consagra una forma de ver el mundo en opuestos irreconciliables. Al ser trasladada al sistema normativo se traduce en dicotomización. La jerarquización de esta diferencia siempre significa subvaloración del término inferior. En el derecho se manifiesta en los lugares que establece para el desarrollo de la convivencia social y política. La dicotomización como forma de ver el mundo niega la diversidad en tanto se es o se está en lo "uno" positivo, o bien se es o se está en lo "otro" subvalorado. ${ }^{15}$

Ahora bien, la evolución del movimiento indigena en América, y el marco juridico de las democracias actuales, fundadas en los derechos fundamentales y en el sistema internacional de los derechos humanos, permiten augurar un cambio en este sentido.

En efecto, el instrumento de los derechos, y especialmente de los derechos colectivos, nos permite plantearnos sin irresponsabilidad el desafio de una tercera vía en la relaciones interétnicas: "el reconocimiento del otro".
Así, en el ámbito de la Doctrina de los Derechos Humanos se ha ido consolidando en el contexto internacional la institución de los derechos colectivos, predicables respecto los pueblos indigenas. El primer paso en este proceso se ha insinuado en el ya tantas veces mencionado Convenio 169 OIT. El cual, en todo caso, contiene limitaciones en cuanto "el movimiento indigena logra cierto grado de maduración y comienza a plantear no sólo el reconocimiento de derechos culturales, sociales y económicos, sino también la reivindicación de derechos políticos vinculados al ejercicio de la libre determinación". ${ }^{16}$ Cucstion que se ha planteado con fuerza en el grupo de trabajo de la ONU, que prepara la Declaración Universal de los Derechos de los Pueblos Indígenas.

Ahora bien, si el principio de igualdad significa reconocer en el otro la capacidad de autonomia y de escoger su plan de vida; no es posible establecer una relación intercultural simétrica si no reconocemos el básico derecho en los pueblos indigcras de autodeterminación (como el Derecho Internacional prédica, en general, para los pueblos). Por lo mismo; si los instrumentos juridicos favorecen la posibilidad de reconocer "al otro", y por tanto, de propiciar un diálogo más igualitario, entonces podemos decir que el derecho puede constituirse en una herramienta útil, que permita avanzar en el desarrollo de los pueblos indígenas, $y$ de las relaciones que con ellas establezcamos quienes no pertenecemos a dichas etnias.

\section{Bibliografía}

BUGUEÑO, M., ESCALONA, L., ESPINOZA, V., MEDINA, M.C., PAL$M A$, R., SALVAT, P. y VALVERDE, F. (1995), Contenidos fundamentales de Derechos Humanos para la educación, Comisión Nacional de Reparación y Reconcillación, Santiago, Chile.

CALBUCUAA, J. (1998), "E! proceso legal de abolición de la propiedad colectiva: El caso mapuche", en Proyecto de documentación N̄uke Mapu, Internet.

DIAZ POLANCO, H. (1998). "Derechos indigenas en la actualidad", en Memoria, Revista mensual de política y cultura, Nümero 117, Proyecto de documentación Ñuke Mapu, Internet.

DWORKIN, R. (1989), Los derechos en serio, Ariel Derecho, Barcelona, España.

EVANS, E. (1986), Los derechos constitucionales, Tomo li, Ed. Juridica de Chile, Santiago, Chile.

FRIES, L. y MATUS, V. (1999), El derecho. Trama y conjura patriarcal, L.OM, Santiago, Chile.

PAREDES, R. (1997), Discriminación en el empleo tras la poítica laboral de ajuste y estabilización de la economia (1991-1997), Pontificia Universidad Católica del Perú, Perú.

PEÑA, C. (1998), "¿Por qué necesitamos a Kant?", en Rovista № 69 del Centro de Estudios Püblicos, Santiago, Chile,

12 CALBUCuRA, J. (1998). "El proceso legal de abolición de la propiedad colectiva: El caso mapuche", en Proyecto de documentación N̂uke Mapu (intemet); pág. 1.

13 CALBUCUFA, S. (1998), ibid, pág. 4.

14 CALBUCUAA, J. (1998), ibid, pàg. 1.

15 FAIES, L. Y MATUS, V. (1999). op. cit.

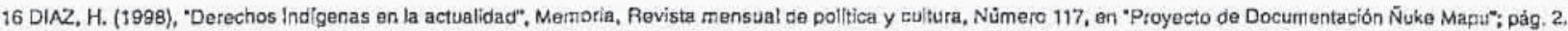




\section{Anexo}

Temuco, ocho de septiembre de mil novecientos noventa y nueve.

Se designa para redactar el fallo acordado en esta causa al Ministro Sr. Leopoldo Llanos Sagristá.

Temuco, ocho de septiembre de mil novecientos noventa y nueve.

\section{VISTOS:}

Se reproduce la parte expositiva, considerandos y citas legales de la sentencia en alzada, con excepción de sus fundamentos $9^{\circ}$ al $13^{\circ}$, ambos inclusive, que se eliminan.

Y se tiene, en su lugar, presente:

1. Que son hechos del proceso, por no haber sido controvertidos y constar, además en el certificado de nacimiento de fs. 1 , certificado de título profesional de fs. 5 , informe de la Contraloría Regional de la Araucanía de fs. 48, informe de la Municipalidad de Lumaco de fs. 52, contrata de asistente social de fs. 54, copias de resoluciones alcaldicias de fs. 55 a fs. 63 , y absolución de posiciones de la querellada de fs. 72 , los siguientes:

a. Que doña Bernardita del Carmen Calfuqueo Llancapán, Asistente Social de la Universidad de la Frontera, fue designada en calidad de contratada a plazo fijo, por el período del $1^{\circ}$ de enero de 1998 al 31 de diciembre del mismo año, con jornada parcial de 22 horas semanales, categoría B, Nivel 15, para desempeñar funciones en el consultorio Lumaco del departamento de Salud Municipal;

b. Que la querellada doña Nelvia Kröll Polanco cumple funciones de encargada de personal del Departamento de Salud de la I. Municipalidad de Lumaco;

c. Que la querellante tiene la calidad de indígena, conforme al artículo $2^{\circ}$ letra A de la Ley $\mathrm{N}^{\circ} 19.253$;

2. Que en cambio, han resultado controvertidos los siguientes hechos: si la querellante era acreedora al pago de viáticos por el cometido funcional fuera del Consultorio Lumaco del Servicio de Salud Municipal; si desempeñó tales cometidos funcionales, y si tales viáticos no le fueron pagados en razón de una actitud manifiestamente discriminatoria de la jefe de personal del Consultorio y querellada de autos.
3. Que conforme a lo dispuesto en el artículo 14 de la ley $\mathrm{N}^{\circ}$ 19.378 , el personal de atención primaria de salud municipal puede ser contratado a plazo fijo o indefinido; y de acuerdo al inciso tercero de la misma disposición, «...se considerarán funcionarios con contrato a plazo fijo, los contratados para realizar tareas iguales o inferiores a un año calendarion. Respecto de las asignaciones de dicho personal a plazo fijo, distintas de las remuneraciones -respecto de las cuales se les aplican las mismas normas que al personal con contrato indefinido, salvo en cuanto a las horas extraordinarias (Arts. 15 inc. $3^{\circ}$ y 40 de la Ley $\mathrm{N}^{\circ}$ 19.378)-, cabe tenner presente que rige supletoriamente, para todo el personal a contrata de salud municipal, sin distinción, la Ley $\mathrm{N}^{\circ} 18.883$, sobre Estatuto Administrativo para funcionarios municipales, regla que establece el artículo $1^{\circ}$ de dicho estatuto; y a su turno, el artículo 96 del mismo cuerpo legal, preceptúa que: «Los funcionarios tendrán derecho a percibir las siguientes asignaciones:... e) Viáticos, pasajes u otros análogos, cuando corresponde, en los casos de comisión de servicios $\mathrm{y}$ de cometidos funcionarios...»;

4. Que, en consecuencia, y aún cuando no es una cuestión propia del presente proceso, existe una base legal para concluir que la querellante, reuniéndose las condiciones que hacen procedente el pago, era acreedora a la asignación por viáticos y pasajes cuando, en cumplimiento de sus funciones, realizaba labores fuera del consultorio Municipal de Lumaco;

5. Que, asimismo, y apreciando de acuerdo a la sana crítica del documento de fs. 21 , «Orden de Cometido Funcional», se ha acreditado que a lo menos en una oportunidad, los días 7 y 8 de mayo de 1999, la querellante debió concurrir a Victoria a efectuar funciones vinculadas al servicio y su cargo, de tal modo que era procedente el pago de las asignaciones de viático y pasajes; habiéndose reconocido por la querellada en la diligencia de absolución de posiciones de fs. 72 y $72 \mathrm{Vta}$. Que tal pago no se efectuó por estimar que éste no le corresponde por la cantidad de horas que fue contratada;

6. Que así las cosas, y habiéndose probado el derecho que impetraba la querellante y la negativa de la querellada a su reconocimiento, cabe dilucidar si tal negativa estuvo motivada por la calidad de indigena de la querellante y constituyó, por ende, una «...discriminación manifiesta e intencionada en contra de los indígenas, en razón de su origen y su cultura», conducta tipificada como falta en el art. $8^{\circ}$ de la Ley $N^{\circ} 19.253$, Ley Indígena, y sancionada con una multa de uno a cinco ingresos mínimos mensuales; 
7. Que orden a establecer lo anterior, y contrariamente a los razonamientos del juez a-quo, este Tribunal de Alzada estima que en el proceso se probó suficientemente la actitud de discriminación manifiesta e intencionada de la querellada, como se desprende de la declaración del testigo Pablo Hernández Lagos, kinesiólogo del Consultorio Municipal de Lumaco, quien fue preciso en deponer que presenció el 13 de mayo de 1998, aproximadamente a las 17 horas, una discusión entre las partes y que oyó a la querellada proferir diversas expresiones ofensivas en contra de la querellante y de los mapuche en general, todas fundadas en dicha calidad raciai y que se consignan en el acta de fs. 65 ;

8. Que el testimonio precedentemente referido, apreciado sana y críticamente, esto es, con arreglo a las máximas de la experiencia y de la lógica, no obstante ser de carácter singular, reúne caracteres suficientes de precisión y veracidad. Lo anterior deriva tanto de las condiciones personales del testigo -profesional que labora en el mismo consuitorio- cuanto por ser coincidente con los otros antecedentes del proceso que revelan que efectivamente la discusión que narra el testigo tuvo lugar en ese sitio y circunstancias, como confesó la inçulpada en su absolución de posiciones. Asimismo, dicho testimonio no logra ser desvirtuado por la testifical de la querellada, como quiera que estos testigos -Mireya Castro, Gladys Lagos y Teresa Tramolao- en lo único que concuerdan es que el día en cuestión -13 de mayo de 1998-, cuando la querellante concurrió a hablar con la querellada, no se encontraban presentes en la conversación entre ambas; por lo que nada presenciaron y nada pudieron decir, por tanto, sobre tal hecho;

9. Que asi las cosas, ha quedado demostrado que la querellada, caprichosa e irracionalmente, se negó a conceder el beneficio de los viáticos a la ofendida, encontrándose tal negativa fundada en la calidad de indigena de ésta, lo cual constituye una discriminación manifiesta e indiscriminada en razón del origen y cultura de la quercliante;

10. Que la conducta de la querellada, además de ser constitutiva de la falta ya expresada y descrita cn la Ley Indigena, vulnera derechos esenciaies consagrados tanto a la Carta Fundamental como en los Instrumentos Internacionales sobre la materia ratificados y promulgados como iey por el Estado de Chile, y de rango constitucional conforme al art. $5^{\circ}$ inc. $2^{\circ}$ de dicha Carta.
En efecto, el artículo $1^{\circ}$ de la Constitución Politica de la República consagra como principio la igualdad de las personas en dignidad y derechos, asegurándose a éstas la igual protección de los mismos en el $\mathrm{N}^{\circ} 3$ del artículo 19 del mismo estatuto. A su turno, el art. 24 de la Convención Americana de Derechos Humanos, junto con consagrar el principio de la igualdad ante la ley, establece el derecho esencial a la igual protección ante ésta sin discriminación.

Finalmente, no puede dejar de mencionarse que la Convención Internacional sobre la Eliminación de todas las Formas de Discriminación Racial, Ley de la República desde 12 de noviembre de 1971, el Estado de Chile se obligó a garantizar a toda persona la igualdad ante la ley, sin distinción de raza, garantizando, entre otros derechos, condiciones equitativas y satisfactorias de trabajo; obligación que en el caso de autos no se habria cumplido por el agente cuestionado del órgano estatal a que aquél pertenece.

Por estas consideraciones, y teniendo además presente lo dispuesto en los arts. $1^{\circ}, 2^{\circ}$ y $8^{\circ}$ de la Ley $N^{\circ} 19.253 ; 55$ de la Ley $\mathrm{N}^{\circ} 15.231$, y siguientes de la Ley $\mathrm{N}^{\circ} 18.287$, SE REVOCA la sentencia apelada de veintidós de octubre de mil novecientos noventa y ocho, escrita de fs. 74 a fs. $77 \mathrm{Vta}$., que no hace lugar a la querellada deducida a fs. 7 y siguientes por doña Bernardita del Carmen Calfuqueo Llancapán en contra de doña Nelvia Kröll Polanco, y se declara en su reemplazo que haciéndose lugar a ella, se condena a la querellada como autora de la falta contemplada en el art. $8^{\circ}$ de la Ley $\mathrm{N}^{\circ} 19.253$ al pago de una multa a beneficio municipal de UN INGRESO MINIMO MENSUAL, y al pago de las costas de la causa.

Redactó el Ministro Señor Leopoldo Llanos Sagristá. Registrese y devuélvase. Rol N ${ }^{\circ} 1274-98$. 